\title{
PROFILE OF PHENOLIC ACIDS AND ANTIOXIDANT CAPACITY IN ORGANS OF COMMON BUCKWHEAT SPROUT
}

\author{
W. Wiczkowski ${ }^{\mathrm{a}}$, D. Szawara-Nowak ${ }^{\mathrm{a}}$, T. Sawicki ${ }^{\mathrm{a}}$, J. Mitrus ${ }^{\mathrm{b}}$, Z. Kasprzykowski $^{\mathrm{b}}$ \\ and M. Horbowicz ${ }^{\text {b** }}$

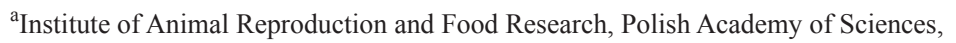 \\ Tuwima 10, 10-748 Olsztyn. Poland \\ ${ }^{\mathrm{b}}$ Faculty of Natural Sciences, Siedlce University of Natural Sciences and Humanities, \\ Prusa 12, 08-110 Siedlce. Poland
}

(Received: 21 March 2015; accepted: 9 June 2015)

\begin{abstract}
The aim of the study was to analyse the content of phenolic acids, total phenolic compounds, proanthocyanidins, and antioxidant capacity in cotyledons and hypocotyl of five cultivars of common buckwheat (Fagopyrum esculentum Moench) sprout. This study presents the first broad profile of phenolic acids occurring in buckwheat microgreen seedlings. In the hypocotyl and cotyledons trans-cinnamic acid and its derivatives: $o_{-}^{-}, m$-, and $p$-coumaric acids (2-, 3-, and 4-hydroxycinnamic), synapic acid (4-hydroxy-3,5-dimethoxycinnamic), caffeic acid (3,4-dihydroxycinnamic), and two isomers of ferulic acid (4-hydroxy-3-methoxycinnamic and 3-hydroxy-4-methoxycinnamic) have been identified. Among the benzoic acid derivatives hydroxybenzoic, protocatechuic (3,4-dihydroxybenzoic), gallic (3,4,5-dihydroxybenzoic) and syringic (4-hydroxy-3,5-dimethoxybenzoic) were found in the organs. In addition to those mentioned, the organs of buckwheat sprouts contain chlorogenic acid as well. The contents of all analysed phenolics were substantially higher in the cotyledons than in the hypocotyl of buckwheat sprouts, except for chlorogenic and caffeic acids. Trans-cinnamic acid was the major phenolic acid in both organs. In the cotyledons, a significant, positive linear correlation between the TEAC, ORAC, PLC-ACW values and content of total phenolic compounds, and also between DPPH and total phenolic acids were found. In the hypocotyl correlations between the DPPH, TEAC, and ORAC and proanthocyanidins content, between TEAC and total phenolic compounds, and between total phenolic acids and PCL-ACW were found.
\end{abstract}

Keywords: antioxidant capacity, common buckwheat, phenolic acids, polyphenols, sprouts

Since many years, plant polyphenols have drawn increasing attention due to their potent antioxidant properties and effects in the prevention of various diseases such as cancer (CAI et al., 2004). Common buckwheat (Fagopyrum esculentum Moench) is an important source of natural phenolic compounds of various biological activities (WIJNGAARD \& ARENDT, 2006). Buckwheat sprouts are rich in antioxidants, and therefore can be classified as a functional food (KIM et al., 2004; JANOvSKA et al., 2010). Buckwheat microgreens are sprouts grown in light for several days. The sprouts are rich in flavonols, flavones, anthocyanins, and phenolic acids (JANOvSKA et al., 2010; Horbowicz et al., 2011a,b; WicZKOWSKI et al., 2014). The buckwheat microgreens are produced and consumed mainly in Japan, Korea, and China, and have been recommended as a new vegetable (KIM et al., 2004).

The content and composition of phenolic acids (PA) in common buckwheat was frequently analysed. However, the most of the results are related to the PA content in seeds (Guo et al., 2012) and leaves or stems of mature plants (Li et al., 2014). In buckwheat sprouts JANOVSKA and co-workers (2010) have found derivatives of cinnamic acid (caffeic, $p$-coumaric,

* To whom correspondence should be addressed. Phone: +48-25 643 1232; e-mail: mhorbowicz@uph.edu.pl 
and ferulic acid) and benzoic acid (vanillic and syringic). In contrast, KIM and co-workers (2008) and SHARma and co-workers (2012) have found and measured only chlorogenic acid.

Various methods have been developed to assess the antioxidant activity, including the oxygen radical absorbance capacity (ORAC) assay or Trolox equivalent antioxidant capacity (TEAC) procedure (NuR ALAM et al., 2013). The ORAC assay has broad application for measuring the antioxidant capacity of food samples and to evaluate in vivo responses to antioxidants from diet. The ORAC method combines both inhibition time and degree of inhibition into a single analysis and it utilizes a biologically relevant radical source (PRIOR et al., 2005). The DPPH method is used mostly for the in vitro antioxidant activity measurement (Nur Alam et al., 2013). The TEAC method is used in the research of oxidative stress caused by free radicals (RE et al., 1999). Photoluminescence assay (PCL) is a possible way to measure relative antioxidant capacities of water soluble (ACW) and lipid soluble (ACL) antioxidants (ZIELINSKA et al., 2008).

The objectives of this study were to quantify phenolic acids and other phenolic compounds, to determine total antioxidant capacity by various assays, as well as to study the relationship between this capacity and the level of analysed phenolic compounds in buckwheat microgreens. To recognize the importance of hypocotyl and cotyledons in the pro-health properties of buckwheat sprouts, the organs were analysed separately.

\section{Materials and methods}

\subsection{Preparation of buckwheat microgreens}

Microgreen sprouts of common buckwheat (Fagopyrum esculentum Moench) cultivars were used in this study. Seeds of Hruszowska cv. were obtained from a local seed store, other cultivars (Kora, Panda, Luba and Emka) were from experimental plots provided by Dr. Joanna Wolińska, Division of Plant Breeding and Seed Production, University of Natural Sciences and Humanities, Siedlce, Poland. Samples of hypocotyl and cotyledons of seven days old buckwheat sprouts were prepared as described earlier (WICZKOWSKI et al., 2014).

\subsection{Determination of phenolic acids}

The content of phenolic acids (free forms and released from the bound forms) were determined according to the modified method of WEIDNER and co-workers (2000). Samples were injected into a HPLC-DAD system (Shimadzu) equipped with a $250 \times 2.0 \mathrm{~mm}$ i.d. Cadenza CD-C18, $3 \mu \mathrm{m}$ column (Imtakt). The HPLC system contained the array detector set at 280 and $320 \mathrm{~nm}$. The analyses were performed at $45^{\circ} \mathrm{C}$ with the flow rate of $0.2 \mathrm{ml} \mathrm{min}^{-1}$. Phenolic acids were eluted in gradient system: solvent A (water/acetonitrile/formic acid, 89:6:5) and solvent B (water/acetonitrile/formic acid, 15:80:5). Gradient was as follows: $2-15-40-75-2-2 \% \mathrm{~B}$ at gradient time, $\mathrm{t}_{\mathrm{G}}=0-77-82-87-92-110 \mathrm{~min}$.

\subsection{Total phenolic and proanthocyanidins analysis}

Total phenolics and proanthocyanidins contents were determined spectrophotometrically using methods previously described (HorBowicz et al., 2011a; b). 


\subsection{Antioxidant capacity assays}

The TEAC assay described by WICZKOwsKI and co-workers (2013), and the DPPH ${ }^{\circ}$ scavenging activity as described by ZIELINSKA and co-workers (2008) were applied. For the PCL assay of the antioxidant activity both ACW (hydrophilic) and ACL (lipophilic) kits were used as well as the protocol of measurement provided by the producer of Photochem apparatus (Analytik Jena, Germany) (ZIELINSKA et al., 2008). The oxygen radical absorbance capacity (ORAC $\left.\mathrm{FL}_{\mathrm{FL}}\right)$ method was used as published by Del CASTILlo and co-workers (2005). All antioxidant assays were carried out in triplicate, and the results were expressed as mmol Trolox g-1 of dry weight (DW).

\subsection{Statistics}

The differences between antioxidant capacities were tested using the Student $t$-test. The correlations between content of particular phenolic compounds and antioxidant capacity results were evaluated with Spearman rank correlation analysis, expressed as rank correlation coefficients. Results with a probability of $\mathrm{P} \leq 0.05$ were assumed to be significant. Statistical processing was performed using the STATISTICA 10.0 programme.

\section{Results and discussion}

In the seven-day microgreens of buckwheat, the level of the total phenolic compounds was about three times higher in cotyledons, than in hypocotyl (Tables 1 and 2). Our results are similar to those published by SHARMA and co-workers (2012), since they are within the range of $84.4-105.4 \mathrm{mg} \mathrm{g}^{-1} \mathrm{DW}$ in the cotyledons, and in the hypocotyl from 33.2 to $39.2 \mathrm{mg} \mathrm{g}^{-1}$ DW. The total content of phenolic acids ranged from 4.90 to $6.01 \mathrm{mg} \mathrm{g}^{-1} \mathrm{DW}$ in the cotyledons, and 2.38 to $2.93 \mathrm{mg} \mathrm{g}^{-1} \mathrm{DW}$ in the hypocotyl. Among analysed phenolic acids, total content of cinnamic acid and its derivatives is about 10-fold higher than the total content of benzoic acid derivatives. The overall level of phenolic acids and proanthocyanidins was about twice as high in the cotyledons as in hypocotyl (Tables 1 and 2).

In the organs of seven-day microgreens of common buckwheat, 13 phenolic acids (PA): trans-cinnamic acid (CA) and its derivatives: $o-, m$ - and $p$-coumaric acids (2-hydroxy-, 3-hydroxy-, and 4-hydroxycinnamic), synapic acid (4-hydroxy-3,5-dimethoxycinnamic), caffeic acid (3,4-dihydroxycinnamic), two isomers of ferulic acid (4-hydroxy-3methoxycinnamic and 3-hydroxy-4-methoxycinnamic), and chlorogenic acid have been identified. Among the benzoic acid derivatives in the organs, hydroxybenzoic, protocatechuic (3,4-dihydroxybenzoic), gallic (3,4,5-dihydroxybenzoic), and syringic (4-hydroxy-3,5dimethoxybenzoic) acids were found. Sum of the contents of CA, caffeic, and chlorogenic acids accounts for over $80 \%$ of total PA level. Most of the acids occur in the cotyledons of buckwheat in higher concentrations than in the hypocotyl. Exceptions to this are caffeic and chlorogenic acids, the contents of which were much higher in hypocotyl than in the cotyledons (Tables 1 and 2).

The results in Tables 1 and 2 indicate that the major phenolic acid in the organs of buckwheat sprouts was CA. Its level in cotyledons was in the range 3104-3850 $\mathrm{g} \mathrm{g} \mathrm{g}^{-1} \mathrm{DW}$, while in the hypocotyls $1257-1651 \mu \mathrm{g} \mathrm{g}^{-1} \mathrm{DW}$. The highest amount of CA in the organs of examined buckwheat cultivars was found in cv. Panda, but in the cotyledons of cultivars differences between results were not statistically significant. The results for CA confirm our previous studies for common buckwheat cv. Hruszowska (HoRBowicz et al., 2011a).

Acta Alimentaria 45, 2016 
Table 1. Content of total phenolic compounds, proanthocyanidins, and phenolic acids in the cotyledons of the sprouts of common buckwheat cultivars $\left(\mu \mathrm{g} \cdot \mathrm{g}^{-1} \mathrm{DW}\right)$

\begin{tabular}{lccccc}
\hline & Luba & Kora & Emka & Panda & Hruszowska \\
\hline Total phenolic compounds* & $99.0 \mathrm{ab}$ & $105.4 \mathrm{a}$ & $84.4 \mathrm{~b}$ & $96.5 \mathrm{ab}$ & $87.6 \mathrm{~b}$ \\
Proanthocyanidins* & $15.7 \mathrm{~b}$ & $20.7 \mathrm{a}$ & $17.0 \mathrm{ab}$ & $18.3 \mathrm{ab}$ & $17.9 \mathrm{ab}$ \\
Total phenolic acids* & $4.90 \mathrm{~b}$ & $6.01 \mathrm{a}$ & $5.18 \mathrm{~b}$ & $5.76 \mathrm{a}$ & $5.64 \mathrm{a}$ \\
\hline & Cinnamic acid derivatives & & & $3569 \mathrm{a}$ \\
trans-Cinnamic & $3104 \mathrm{a}$ & $3704 \mathrm{a}$ & $3484 \mathrm{a}$ & $3850 \mathrm{a}$ & $406.9 \mathrm{~b}$ \\
2-Hydroxycinnamic & $371.5 \mathrm{~b}$ & $436.7 \mathrm{a}$ & $316.0 \mathrm{c}$ & $309.5 \mathrm{c}$ & $38.4 \mathrm{e}$ \\
3-Hydroxycinnamic & $104.6 \mathrm{a}$ & $95.3 \mathrm{~b}$ & $54.5 \mathrm{~d}$ & $77.6 \mathrm{c}$ & $39.2 \mathrm{~d}$ \\
4-Hydroxycinnamic & $96.1 \mathrm{a}$ & $22.0 \mathrm{~d}$ & $51.8 \mathrm{~b}$ & $46.3 \mathrm{c}$ & $162.3 \mathrm{~b}$ \\
3,4-Dihydroxycinnamic & $179.3 \mathrm{a}$ & $150.4 \mathrm{c}$ & $75.5 \mathrm{e}$ & $140.9 \mathrm{~d}$ & $31.8 \mathrm{~b}$ \\
4-Hydroxy-3-methoxycinnamic & $26.8 \mathrm{~b}$ & $66.6 \mathrm{a}$ & $34.7 \mathrm{~b}$ & $88.6 \mathrm{a}$ & $199.3 \mathrm{~b}$ \\
3-Hydroxy-4-methoxycinnamic & $134.5 \mathrm{c}$ & $233.2 \mathrm{a}$ & $133.8 \mathrm{c}$ & $173.7 \mathrm{bc}$ & $452.5 \mathrm{~b}$ \\
4-Hydroxy-3,5-dimethoxycinnamic & $436.2 \mathrm{~b}$ & $566.8 \mathrm{a}$ & $460.3 \mathrm{~b}$ & $361.9 \mathrm{c}$ & $137.4 \mathrm{~b}$ \\
Chlorogenic & $163.9 \mathrm{~b}$ & $163.8 \mathrm{~b}$ & $205.1 \mathrm{a}$ & $137.4 \mathrm{~b}$ & $18.9 \mathrm{c}$ \\
\hline
\end{tabular}

Different letters within rows indicate statistically significant difference at $\mathrm{P}<0.05, \mathrm{n}=3$, according to the Student $t$-test. * the contents are expressed in $\mathrm{mg}^{\circ} \mathrm{g}^{-1} \mathrm{DW}$

o-Coumaric (2-hydroxycinnamic) and synapic (4-hydroxy-3,5-dimethoxycinnamic) acids also occur in the cotyledons of buckwheat in relatively high contents (Table 1). Their contents in examined cultivars were $309.5-436.7 \mu \mathrm{g} \mathrm{g}^{-1} \mathrm{DW}$ and $361.9-566.8 \mu \mathrm{g} \mathrm{g}^{-1} \mathrm{DW}$, respectively. In the case of hypocotyl, the caffeic (3,4-dihydroxycinnamic) and chlorogenic acids: 391.9-664.6 $\mu \mathrm{g} \mathrm{g}^{-1} \mathrm{DW}$ and 358.2-515.4 $\mu \mathrm{g} \mathrm{g}^{-1} \mathrm{DW}$, respectively (Table 2), are in larger concentrations. The last results are lower than those published for 6-10 days old Japanese buckwheat seedlings (KIm et al., 2008). In the study of SHARma and co-workers (2012) content of chlorogenic acid in 10-day microgreens of common buckwheat was $1.56 \mathrm{mg} \mathrm{g}^{-1} \mathrm{DW}$, while in leafy greens (21-days-old plants) it rapidly declined to $0.03 \mathrm{mg} \mathrm{g}^{-1}$ DW. These results indicate that the decisive impact on the content of chlorogenic acid is the age of the plant, and likely its genetic diversity.

There are little available data on the content of PA in buckwheat sprouts (JANOVSKA et al., 2010). In sprouts of common and tartary buckwheat the following PA were found: caffeic, p-coumaric, ferulic acid, vanillic (4-hydroxy-3-methoxybenzoic), and syringic (4-hydroxy3,5-dimethoxybenzoic) acids. However, their contents did not exceed $10 \mu \mathrm{g} \mathrm{g}^{-1} \mathrm{DW}$. We have not found measurable content of vanillic acid, but the full profile of phenolic acids was significantly wider than that of other researchers (KIM et al., 2004; JANOvSKA et al., 2010). Most of the data on the content of these acids in buckwheat concerns their presence in seeds (Guo et al., 2012) or in organs of mature plant (Li et al., 2014). 
Table 2. Content of total phenolic compounds, proanthocyanidins, and phenolic acids in the hypocotyl of the sprouts of common buckwheat cultivars $\left(\mu \mathrm{g} \cdot \mathrm{g}^{-1} \mathrm{DW}\right)$

\begin{tabular}{|c|c|c|c|c|c|}
\hline & Luba & Kora & Emka & Panda & Hruszowska \\
\hline Total phenolic compounds* & $38.3 \mathrm{a}$ & $39.2 \mathrm{a}$ & $33.2 \mathrm{~b}$ & $39.2 \mathrm{a}$ & $35.8 \mathrm{~b}$ \\
\hline Proanthocyanidins* & $9.31 \mathrm{~b}$ & $9.82 \mathrm{~b}$ & $8.33 \mathrm{c}$ & $10.95 \mathrm{a}$ & $9.62 \mathrm{~b}$ \\
\hline Total phenolic acids* & $2.93 \mathrm{a}$ & $2.53 \mathrm{bc}$ & $2.38 \mathrm{c}$ & $2.74 \mathrm{ab}$ & $2.91 \mathrm{a}$ \\
\hline \multicolumn{6}{|c|}{ Cinnamic acid derivatives } \\
\hline trans-Cinnamic & $1368 \mathrm{a}$ & $1316 \mathrm{a}$ & $1257 \mathrm{a}$ & $1651 \mathrm{a}$ & $1382 \mathrm{a}$ \\
\hline 2-Hydroxycinnamic & $5.3 \mathrm{a}$ & $5.1 \mathrm{a}$ & $3.7 \mathrm{a}$ & $4.6 \mathrm{a}$ & $3.6 \mathrm{~b}$ \\
\hline 3-Hydroxycinnamic & $31.6 \mathrm{a}$ & $17.0 \mathrm{~b}$ & $13.2 \mathrm{~b}$ & $18.0 \mathrm{~b}$ & $17.4 \mathrm{~b}$ \\
\hline 4-Hydroxycinnamic & $29.7 \mathrm{a}$ & $25.0 \mathrm{a}$ & $18.2 \mathrm{~b}$ & $27.1 \mathrm{a}$ & $25.0 \mathrm{a}$ \\
\hline 3,4-Dihydroxycinnamic & $676.8 \mathrm{a}$ & $499.6 \mathrm{~b}$ & $437.8 \mathrm{c}$ & $391.9 \mathrm{c}$ & $664.6 \mathrm{a}$ \\
\hline 4-Hydroxy-3-methoxycinnamic & $12.2 \mathrm{ab}$ & $9.6 \mathrm{~b}$ & $10.2 \mathrm{ab}$ & $2.9 \mathrm{c}$ & $16.9 \mathrm{a}$ \\
\hline 3-Hydroxy-4-methoxycinnamic & $51.0 \mathrm{a}$ & $36.3 \mathrm{a}$ & $21.9 \mathrm{~b}$ & $48.6 \mathrm{a}$ & $31.8 \mathrm{ab}$ \\
\hline 4-Hydroxy-3,5-dimethoxycinnamic & $110.4 \mathrm{a}$ & $78.7 \mathrm{~b}$ & $78.1 \mathrm{~b}$ & $88.6 \mathrm{~b}$ & $126.9 \mathrm{a}$ \\
\hline Chlorogenic & $515.4 \mathrm{a}$ & $365.8 \mathrm{~d}$ & $414.1 \mathrm{c}$ & $358.2 \mathrm{~d}$ & $469.0 \mathrm{~b}$ \\
\hline \multicolumn{6}{|l|}{ Benzoic acid derivatives } \\
\hline 4-Hydroxybenzoic & $62.9 \mathrm{~b}$ & $79.0 \mathrm{a}$ & $58.3 \mathrm{~b}$ & $69.1 \mathrm{ab}$ & $89.8 \mathrm{a}$ \\
\hline 3,4-Dihydroxybenzoic & $58.7 \mathrm{~b}$ & $83.1 \mathrm{a}$ & $55.6 \mathrm{~b}$ & $58.4 \mathrm{~b}$ & $87.3 \mathrm{a}$ \\
\hline 3,4,5-Trihydroxybenzoic & $5.2 \mathrm{~d}$ & $7.0 \mathrm{c}$ & $4.7 \mathrm{~d}$ & $21.0 \mathrm{a}$ & $9.1 \mathrm{~b}$ \\
\hline 4-Hydroxy-3,5-dimethoxybenzoic & $4.7 \mathrm{ab}$ & $3.5 \mathrm{~b}$ & $3.9 \mathrm{~b}$ & $2.8 \mathrm{~b}$ & $5.6 \mathrm{a}$ \\
\hline
\end{tabular}

Different letters within rows indicate statistically significant difference at $\mathrm{P}<0.05, \mathrm{n}=3$, according to the Student $t$-test. * the contents are expressed in $\mathrm{mg}^{\circ} \mathrm{g}^{-1} \mathrm{DW}$

Among the analysed phenolic acids, special attention should be paid to chlorogenic, $m$-coumaric (2-hydroxycinnamic), and caffeic (3,4-dihydroxycinnamic) acids. Chlorogenic acid protects against degenerative, age-related diseases in animals, when supplied in their diet, and lowers blood pressure (ONAKPOYA et al., 2014). In a study of several antioxidants applied to cells in vitro, only chlorogenic, 2-hydroxycinnamic, and 3,4-dihydroxycinnamic acids increased the protein expression of two tested DNA repair enzymes (BERNSTEIN et al., 2007). 3,4-Dihydroxycinnamic acid has also a potential pharmacological effect due to inhibition of cancer cell proliferation (RAJENDRA PRASAD et al., 2011). The observation that the content of chlorogenic and 3,4-dihydroxycinnamic acids are much higher in hypocotyl than in the cotyledons indicates that the consumption of this part may also be important. Among the examined buckwheat cultivars, particularly high content of these phenolic acids was noted in cv. Luba and Hruszowska.

The use of several methods for the analysis of antioxidant capacity in this study allows to select the one that fits best the content and composition of polyphenols. PrIOR and coworkers (2005) have proposed TEAC, ORAC, and total phenol by Folin-Ciocalteu assay for the analysis of antioxidant activity. In our study, we used those mentioned as well as three other methods: DPPH, PCL-ACL, and PCL-ACW. All the methods were applied and compared in the cotyledons and hypocotyl of common buckwheat microgreens. 
The results of antioxidant capacity were higher in cotyledons than in hypocotyl for all studied buckwheat cultivars (Table 3). Among the methods used, relatively small differences were found between the cotyledons and hypocotyl in the values of DPPH. Much larger differences occurred in the case of TEAC and ORAC values, which were ca. 3-fold higher in cotyledons than in hypocotyl. The PCL-ACW and PCL-ACL values were twice higher in cotyledons than hypocotyl. In the examined cultivars, the highest level of DPPH was found in cv. Panda. Also, in the case of PCL-ACL, the highest values were reported in the cv. Panda. In the case of ORAC method, the highest values were observed in cotyledons of cv. Luba, while using the TEAC method in cotyledons of cv. Kora. There were no differences between cultivars in the case of the results of antioxidant activity measured by the method of PCLACW, TEAC, and ORAC in hypocotyl of buckwheat sprouts (Table 3). After comparison of the content of phenolic compounds with antioxidant activity data, the presence of a statistically significant, positive correlation between content of total phenolic compounds and the TEAC $(\mathrm{R}=0.85)$, ORAC (0.84), and PLC-ACW (0.75) values, and between DPPH and total phenolic acids $(\mathrm{R}=0.75)$ were found. In the hypocotyl correlations between proanthocyanidins content and DPPH (0.70), TEAC (0.73), and ORAC (0.64), between TEAC and total phenolic compounds (0.82), as well as between total phenolic acids and PCL-ACW (0.75) were found. The correlation between the content of total phenolic compunds and antioxidant activity has been noted previously in fruit and vegetables (KAUR \& KAPOOR, 2000).

Table 3. The results of different assays of antioxidant capacity in the sprout organs of common buckwheat cultivars (mM Trolox/g DW)

\begin{tabular}{|c|c|c|c|c|c|}
\hline Applied assay & Luba & Kora & Emka & Panda & Hruszowska \\
\hline \multicolumn{6}{|c|}{ Cotyledons } \\
\hline DPPH & $0.08 \mathrm{a}$ & $0.09 \mathrm{a}$ & $0.09 \mathrm{a}$ & $0.09 \mathrm{a}$ & $0.09 \mathrm{a}$ \\
\hline TEAC & $1.15 \mathrm{a}$ & $1.08 \mathrm{a}$ & $0.87 \mathrm{~b}$ & $1.02 \mathrm{ab}$ & $0.91 \mathrm{~b}$ \\
\hline ORAC & $1.47 \mathrm{ab}$ & $1.63 \mathrm{a}$ & $1.21 \mathrm{~b}$ & $1.22 \mathrm{~b}$ & $1.22 \mathrm{~b}$ \\
\hline PCL-ACL & 0.89 a & $0.91 \mathrm{a}$ & $0.82 \mathrm{a}$ & $0.94 \mathrm{a}$ & $0.86 \mathrm{a}$ \\
\hline PCL-ACW & $0.15 \mathrm{a}$ & $0.14 \mathrm{a}$ & $0.11 \mathrm{a}$ & $0.12 \mathrm{a}$ & $0.13 \mathrm{a}$ \\
\hline \multicolumn{6}{|c|}{ Hypocotyl } \\
\hline DPPH & $0.06 \mathrm{~b}$ & $0.06 \mathrm{~b}$ & $0.06 \mathrm{~b}$ & $0.09 \mathrm{a}$ & $0.06 \mathrm{~b}$ \\
\hline TEAC & $0.36 \mathrm{a}$ & $0.37 \mathrm{a}$ & $0.32 \mathrm{a}$ & $0.37 \mathrm{a}$ & $0.35 \mathrm{a}$ \\
\hline ORAC & $0.41 \mathrm{a}$ & $0.42 \mathrm{a}$ & $0.33 \mathrm{~b}$ & $0.44 \mathrm{a}$ & $0.40 \mathrm{a}$ \\
\hline PCL-ACL & $0.40 \mathrm{~b}$ & $0.36 \mathrm{~b}$ & $0.37 \mathrm{~b}$ & $0.54 \mathrm{a}$ & $0.41 \mathrm{~b}$ \\
\hline PCL-ACW & $0.06 \mathrm{a}$ & $0.06 \mathrm{a}$ & $0.05 \mathrm{a}$ & $0.05 \mathrm{a}$ & $0.07 \mathrm{a}$ \\
\hline
\end{tabular}

Different letters within rows indicate statistically significant difference at $\mathrm{P}<0.05, \mathrm{n}=3$, according to the Student $t$-test

Results of antioxidant activity determined by ORAC method were higher compared to the other methods used in this study. In other types of food, ORAC values were also higher in comparison to DPPH, TEAC values when antioxidant activity was determined using different assays (Zulueta et al., 2009; WicZKowski et al., 2013). The results of antioxidant activity are influenced by many factors, including the inclusion of antioxidants in the 
measurement phase, the colloidal properties of the substrate, and the conditions of the oxidation. Also, the type of procedure and the kind of free radical generator or oxidant used in assays affect the results (Prior et al., 2005).

Comparison of obtained results of antioxidant activity to those in the literature is difficult. The reason is that they are mainly related to seeds, and were obtained by using the DPPH assay (Holasova et al., 2002). The relationship between the level of total phenols and ORAC results is usually significant (Prior et al., 2005), as well as between TEAC values and total phenolics (CAI et al., 2004). The obtained data of antioxidant capacity allow the buckwheat sprouts to be included in the group of plants with the highest antioxidant capacity, which confirms data shown in previous studies (ZIELIŃSKI et al., 2005).

\section{Conclusions}

This study presents the first broad profile of phenolic acids occurring in buckwheat microgreens seedlings. Furthermore, it is concluded that assays of antioxidant activities of buckwheat microgreens might be estimated indirectly. In cotyledons, all examined assays of antioxidant activity, except for DPPH, were associated with total phenolics level. Results of the DPPH assay were strongly correlated to content of total phenolic acids and proanthocyanidins level in the cotyledons.

\section{References}

Bernstein, H., Crowley-Skillicorn, C., Bernstein, C., Payne, C.M., Dvorak, K. \& Garewal, H. (2007): Dietary compounds that enhance DNA repair and their relevance to cancer and aging. -in: LANDSEER, B.R. (Ed.) New research on DNA repair. Chapter IV, Nova Science Publishers, Inc., Hauppage NY, pp. 99-113.

CAI, Y., Luo, Q., Sun, M. \& Corke, H. (2004): Antioxidant activity and phenolic compounds of 112 traditional Chinese medicinal plants associated with anticancer. Life Sci., 74, 2157-2184.

Del Castillo, M.D., Gordon, M.H. \& Ames, J.M. (2005): Peroxyl radical-scavenging activity of coffee brews. Eur. Food Res. Technol., 221, 471-477.

Guo, X.D., Wu, C.S., Ma, Y.J., Parry, J., Xu, Y.Y., Liu, H. \& WANG, M. (2012): Comparison of milling fractions of tartary buckwheat for their phenolics and antioxidant properties. Food Res. Int., 49, 53-59.

Holasova, M., Fiedlerova, V., Smrcinova, H., Orsak, M., Lachman, J. \& Vavreinova, S. (2002): Buckwheat - the source of antioxidant activity in functional foods. Food Res. Int., 35, $207-211$.

Horbowicz, M., Chrzanowski, G., Koczkodaj, D. \& Mitrus, J. (2011a): Effect of methyl jasmonate vapors on content of phenolic compounds in seedlings of common buckwheat (Fagopyrum esculentum Moench). Acta Soc. Bot. Pol., 80, 5-9.

Horbowicz, M., Wiczkowski, W., Koczkodaj, D. \& Saniewski, M. (2011b): Effects of methyl jasmonate on accumulation of flavonoids in seedlings of common buckwheat (Fagopyrum esculentum Moench). Acta Biol. Hung., 62, 265-278.

JANOvska, D., S̆ToČKovÁ, L. \& Stehno, Z. (2010): Evaluation of buckwheat sprouts as microgreens. Acta Agr. Slov., 95, 157-162.

Kaur, C. \& KaPoor, H.C. (2000): Antioxidant activity and total phenolic content of some Asian vegetables. Int. J. Food Sci. Tech., 37, 153-161.

Kim, S.L., Kim, S.K. \& PARK, C.H. (2004): Introduction and nutritional evaluation of buckwheat sprouts as a new vegetable. Food Res. Int., 37, 319-327.

Kim, S. J., Zaidul, I.S.M., Suzuki, T., Mukasa, Y., Hashimoto, N., Takigawa, S., Noda, T., Chie, M.E. \& Yamauchi, H. (2008): Comparison of phenolic compositions between common and tartary buckwheat (Fagopyrum) sprouts. Food Chem., 110, 814-820. 
Li, X., Kim, J.K., PARK, S.-Y., Zhao, S., Kim, Y.B., Lee, S. \& PARK, S.U. (2014): Comparative analysis of flavonoids and polar metabolite profiling of tanno-original and tanno-high rutin buckwheat. J. Agr. Food Chem., 62, 2701-2708

Nur Alam, M., Bristi, N.J. \& Rafiquzzaman, M. (2013): Review on in vivo and in vitro methods evaluation of antioxidant activity. Saudi Pharm. J., 21, 143-152.

Onakpoya, I.J., Spencer, E.A., Thompson, M.J. \& Heneghan, C.J. (2014): The effect of chlorogenic acid on blood pressure: a systematic review and meta-analysis of randomized clinical trials. J. Hum. Hypertens., 29, 77-81.

Prior, R.L.,Wu, X. \& Schaich, K. (2005): Standardized methods for the determination of antioxidant capacity and phenolics in foods and dietary supplements. J. Agr. Food Chem., 53, 4290-4302.

Re, R., Pellegrini, N., Pannala, A., Yang, M. \& Rice-Evans, C. (1999): Antioxidant activity applying an improved ABTS radical cation decolorization assay. Free Radical Bio. Med., 26, 1231-1237.

Rajendra Prasad, N., Karthikeyan, A., Karthikeyan, S. \& Reddy, B.V. (2011): Inhibitory effect of caffeic acid on cancer cell proliferation by oxidative mechanism in human HT-1080 fibrosarcoma cell line. Mol. Cell Biochem. 349, 11-19.

Sharma, P., Ghimeray, A.K., Gurung, A., Jin, C.W., Rho, H.S. \& Cho, D.H. (2012): Phenolic contents, antioxidant and $\alpha$-glucosidase inhibition properties of Nepalese strain buckwheat vegetables. Afr. J. Biotechnol., 11, 184190.

Weidner, S., Amarowicz, R., Karamać, M. \& Frączek, E. (2000): Changes in endogenous phenolic acids during development of Secale cereale caryopses and after dehydration treatment of unripe rye grains. Plant Physiol. Bioch., 38, 595-602.

Wiczkowski, W., Szawara-Nowak, D., Dębski, H., Mitrus, J. \& Horbowicz, M. (2014): Comparison of flavonoids profile in sprouts of common buckwheat cultivars and wild tartary buckwheat. Int. J. Food Sci. Tech., 49, 1977-1984.

Wiczkowski, W., Szawara-Nowak, D. \& Topolska, J. (2013): Red cabbage anthocyanins: profile, isolation, identification, and antioxidant activity. Food Res. Int., 51, 303-309.

WijngaArd, H.H. \& Arendt, E.K. (2006): Buckwheat. Cereal Chem., 83, 391-401.

Zielinska, D., Wiczkowski, W. \& PiskuŁA, M.K. (2008): Determination of the relative contribution of quercetin and its glucosides to the antioxidant capacity of onion by cyclic voltammetry and spectrophotometric methods. J. Agr. Food Chem., 56, 3524-3531.

Zielinski, H., PiskuŁa, M.K. \& KozŁowska, H. (2005): Biologically active compounds in Cruciferae sprouts and their changes after thermal treatment. Pol. J. Food Nutr. Sci., 14/55, 375-380.

Zulueta, A., Esteve, M.J. \& Frigola, A. (2009): ORAC and TEAC assays comparison to measure the antioxidant capacity of food products. Food Chem., 114, 310-316. 